\title{
Representação social do cuidado e do cuidador familiar do idoso
}

\author{
Helga Cristina Hedler \\ Universidade Católica de Brasília (UCB) \\ Marlene de Jesus Silva Santos \\ Universidade de Brasília (UnB)
}

\author{
Vicente de Paula Faleiros \\ Universidade Católica de Brasília (UCB) \\ Maria Aparecida de Araújo Almeida \\ Assistente Social
}

\section{Representação social do cuidado e do cuidador familiar do idoso}

Resumo: O presente artigo aborda as representações sociais do cuidado e do cuidador familiar da pessoa idosa. A pesquisa é de caráter qualitativo com a evocação dos termos cuidado e cuidador por meio de entrevista aplicada na residência de quinze idosos com dependência funcional de saúde, juntamente com seus cuidadores familiares. Os resultados apontam, como núcleo central das representações sociais, os sentimentos de amor, carinho, paciência e saúde. O significado social do cuidado, em conflito com a vivência do sofrimento dos cuidadores, assume uma função que lhes traz a sobrecarga física e emocional. A desigualdade de gênero presente entre os cuidadores também implica a necessidade de se refletir sobre os cuidadores como questão de políticas públicas.

Palavras-chave: Cuidador familiar. Cuidado. Pessoa idosa. Núcleo central. Representação social.

\section{Social Representation of Care Recipients and of Family Care Providers for the Elderly}

Abstract: This article addresses the social representation of care recipients and of family care providers for the elderly. It is a qualitative study that evokes the terms care recipient and care provider in interviews in a residence for fifteen elderly people with functional health dependencies, along with their family care providers. The results indicate, as a central core of the social representations, feelings of love, care, patience and health. The social meaning of care recipient, in conflict with the experience of suffering of the care providers, assumes a function that creates a physical and emotional burden for these care providers. The gender inequality present among these care providers also implies a need to reflect on care providers as a public policy issue.

Keywords: Family care provider. Care recipient. Elderly person. Social representation. 


\section{Introdução}

Estudos sobre as representações sociais do cuidador familiar de idosos têm sido desenvolvidos nos últimos anos em áreas da Psicologia, Saúde e Serviço Social (MAZZA; LEFÉVRE, 2005; CATITA, 2008; SOUZA; MENEZES, 2009), contribuindo para trazer conhecimento sobre o universo simbólico que rege as relações entre cuidador, família e idoso. No entanto, pouco se conhece quando se trata do cuidador familiar da pessoa idosa, de sua relação com a família, da imagem que representa essa atividade e de suas implicações em termos das demandas de esforços físicos, psicológicos e do quanto enseja o rearranjo das escolhas em relação a emprego, estudos e vida pessoal. O ato de cuidar está inserido em todas as culturas e é realizado sob diferentes formas e expressões (MAFRA, 2011). Borges (2011) entende o cuidar da pessoa idosa como uma tarefa realizada com o objetivo de melhorar a qualidade de vida do idoso dependente. Para São José (2012), o cuidar é ajudar a pessoa idosa a realizar tarefas que não consegue desempenhar sozinha e as quais são primordiais para a manutenção do bem-estar no seu cotidiano, como as atividades da vida diária (AVD), tais como higiene pessoal, ingestão de alimentos, mobilidade física, entre outros. Inclui também a ajuda nas atividades instrumentais da vida diária (AIVD), como fazer compras, preparar refeição, tratar da roupa etc., além de dar atenção à pessoa idosa, mostrando-se atento a suas preocupações, ajudá-la a lidar com as tensões emocionais e, ainda, ficar atento aos cuidados de terceiros prestados a elas. O cuidar está relacionado a questões sociais, de gênero, idade e cultural, a laços de parentesco ou de muita proximidade. O cuidado formal é exercido por profissional e pessoal especializado, de acordo com um protocolo e um Código de Ética. O cuidado despendido em casa ou entre familiares e amigos é denominado cuidado informal, sendo na maioria das vezes representado como obrigação, entretanto comporta também a expressão de afeto, proteção, reciprocidade e gratuidade (MARQUES; TEIXEIRA; SOUZA, 2012). Além de ser uma tarefa motivada por normas sociais, o cuidador se sente cumpridor de uma obrigação social e moral em que predomina um dever de reciprocidade, necessidade de evitar o sentimento de culpa e uma relação empática e afetiva entre o cuidador e o idoso (FERREIRA; WONG, 2007; GUEDES; DAROS, 2009; MAFRA, 2011).

O cuidado informal tem como contexto a família e se pratica normalmente no domicílio do idoso ou dos cuidadores/cuidadoras. Mioto (2010) ressalta a diversidade das configurações familiares como um espaço muito complexo, pois a família se constrói e se modifica de acordo com os contextos históricos e o seu cotidiano, mediante relações entre a família e a sociedade, seus membros e a sociedade e, por exemplo, entre Estado, trabalho e mercado. Enfatiza ainda que a família tem papel importante na estrutura da sociedade quanto aos aspectos sociais, políticos e econômicos e que as deficiências das políticas públicas são cobertas pela família. Segundo Gomes (2009), para a Política Nacional de Assistência Social (PNAS) a família é o ponto estratégico de amparo aos seus membros, assim como é alvo de Políticas de proteção e de cobranças do Estado e da sociedade. No entanto, alguns autores (BORN, 2008; GOMES, 2009) discutem acerca da centralidade familiar como espaço primordial de proteção aos seus membros. Na Constituição Brasileira de 1988 (art. 229) está contemplado o dever de reciprocidade entre pais e filhos e no artigo 230 a prioridade dos domicílios para os "programas de amparo aos idosos" (sic.) (BRASIL, 1988). Segundo Mioto (2010), uma das críticas a respeito da centralidade familiar, como provedora de proteção aos seus membros, está relacionada ao retrocesso da atuação do Estado nas garantias de direitos sociais, quando a política pública de caráter universal passa a ser uma política pública focalizada, fortalecendo a atuação do mercado como provedor da proteção social, com objetivo do cobrir a sua falta na garantia dos direitos sociais. Nesse sentido, entende-se como uma contradição a proposta protetiva apresentada pela Política Nacional de Assistência Social (PNAS):

a centralidade da família é garantida à medida que na Assistência Social, com base em indicadores das necessidades familiares, desenvolva numa política de cunho universalista, que em conjunto com as transferências de rendas em patamares aceitáveis se desenvolva, prioritariamente, em redes socioassistenciais que suportem as tarefas cotidianas de cuidado e que valorizem a convivência familiar e comunitária (BRASIL, 2004, p. 42).

A ausência do Estado e a culpabilização da família são a tônica na discussão do cuidado. Perpassa ainda a questão de gênero quando se indaga quem são os cuidadores familiares de pessoas idosas. Nestas três vertentes é que se agregam as discussões teóricas e os achados de pesquisas atuais sobre o tema, com o objetivo de compreender as representações sociais da sua atividade, o cuidado, e da imagem, o cuidador familiar. 


\section{A realidade do cuidado familiar}

De acordo com o Estatuto do Idoso, pessoas idosas são aquelas que têm 60 anos ou mais. Na Pesquisa Nacional por Amostra de Domicílios (PNAD), de 2009 (INSTITUTO BRASILEIRO DE GEOGRAFIA E ESTATÍSTICA, 2010a), a população brasileira tinha por volta de 21 milhões de pessoas com 60 anos ou mais. Entre 1999 a 2009, o peso relativo dos idosos no conjunto da população passou de 9,1\% para 11,3\% (IBGE, 2010b). O envelhecimento é um segmento onde o indivíduo vivencia a última etapa de declínio de várias funções que aumenta a fragilidade e possibilidade de morte. No entanto, nessa etapa da vida as pessoas podem viver com total autonomia, ou com baixa ou nenhuma capacidade para lidar com as atividades mais básicas do cotidiano (CAMARANO; PASINATO, 2004). Para esse segundo grupo de pessoas, a presença de um cuidador que ajude na realização das atividades cotidianas torna-se fundamental. Ferreira e Wong (2007) fazem uma prospecção sobre cuidadores informais em relação à população idosa para o período compreendido entre 2000 a 2015 e destacam o aumento da população idosa que necessitará de cuidado, inclusive frente à diminuição da quantidade de potenciais cuidadores familiares, levando-se em conta as mudanças na composição das famílias.

$\mathrm{Na}$ família, o cuidado com a pessoa idosa pode ser realizado por mais de uma pessoa, no entanto, a maior parte das tarefas de cuidar é realizada normalmente por apenas uma pessoa e em geral por uma mulher (KRMPOTIC; DE IESO, 2010; FLORIANO et al., 2012). Nesse contexto, encontra-se o cuidador familiar de idosos, também denominado cuidador informal (FERREIRA; WONG, 2007) ou principal (BORN, 2008), que recebe essa denominação por não obter nenhuma remuneração para desenvolver a tarefa de cuidador. Portanto, também podem ser incluídos nessa categoria, além das pessoas com laços de parentesco, os amigos e os vizinhos que desenvolvam a atividade como voluntários (BORN, 2008). Um fator bastante citado sobre o cuidador familiar é a sobrecarga de trabalho que os acomete (CARDOSO; ROSALINI; PEREIRA, 2010; FLORIANO et al., 2012). É comum nas famílias um único membro assumir a maior parte da responsabilidade do cuidado. A divisão de tarefas relacionadas ao cuidado com a pessoa idosa é importante para que o cuidador não se sinta sobrecarregado (BORGES, 2011). São muitas as tarefas realizadas pelo cuidador: há aquelas em que o cuidador necessitará de ajuda para realizá-las, outras poderão ser feitas por uma pessoa apenas. Algumas tarefas são cotidianas como a higiene, a alimentação e os cuidados com os remédios; outras, porém, são realizadas esporadicamente, por exemplo, levar o idoso ao médico (MAFRA, 2011). O acúmulo de tarefas por uma única pessoa pode provocar problemas relacionados à saúde, acarretar problemas à vida pessoal, profissional e familiar em função do cuidador anular sua vida pessoal, profissional e familiar para garantir a sobrevida e a qualidade de vida do idoso sob seus cuidados (CARDOSO; ROSALINI; PEREIRA, 2010; FLORIANO et al., 2012).

Cuidar de uma pessoa idosa da família pode trazer outras consequências, como conflitos no âmbito emocional, pois o cuidador pode experimentar sentimentos positivos como satisfação por cuidar de uma pessoa idosa da família e ao mesmo tempo sentimentos negativos como: sensação de impotência, tristeza, solidão e preocupação. No âmbito da vida profissional, os que trabalham fora de casa, tendem a falhar tanto nas tarefas do cuidado com o idoso quanto no desempenho profissional (atrasos frequentes, faltas etc.). Em alguns casos, em virtude da dificuldade em conciliar a tarefa de cuidador e de profissional fora de casa, há tendência a diminuir sua carga horária no trabalho ou mesmo deixar o emprego, o que pode acarretar dificuldades financeiras para o cuidador e sua família. No âmbito do lazer, não é raro que cuidadores familiares diminuam suas horas dedicadas ao lazer, sentindo-se isolados de amigos e de todos que o cercam (BORN, 2008). Considerando os novos arranjos familiares advindos da redução do número de filhos, menor taxa de fecundidade, aumento da longevidade, exigência do mercado de trabalho e pobreza (FALEIROS, 2014) questiona-se a extrema vulnerabilidade psicológica e situacional em que se encontram tanto o cuidador quanto o idoso, quando se trata de uma díade onde o cuidador não possui muitas vezes as condições materiais, físicas e psicológicas para exercer esse cuidado. Até onde vai a responsabilidade da família, até onde vai a responsabilidade do Estado?

Mazza e Lefévre (2005) investigaram as representações sociais dos cuidadores familiares de idosos com idade a partir de 70 anos e com incapacidade funcional. $\mathrm{O}$ ato de cuidar estava ligado ao sentimento de gratidão pelos cuidados recebidos na infância. Outro fator que a pesquisa revelou foi o cuidado leigo, o cuidado prestado por meio da boa vontade. Resultados de pesquisas (MASSA; LEFÉVRE, 2005; FERREIRA; WONG, 2007; CARDOSO; ROSALINI; PEREIRA, 2010; FLORIANO et al., 2012) mostram que os cuidadores familiares necessitam de ajuda, por parte de profissionais de forma multidisciplinar, assim como das demais pessoas da família e do Estado: "Muitos cuidadores [...] não se reconhecem como ocupantes de um papel social, ao contrário, veem suas ações como uma extensão das relações pessoais e familiares" (YUASO, 2006, p. 166). Soma-se a esse quadro o fato de que as instituições sociais deixam de cumprir com o seu papel ao 
reforçar essa visão, não reconhecendo que além de o cuidador atender as demandas objetivas e imediatas das pessoas idosas, também trazem soluções para um problema que é de toda a sociedade.

Algumas instituições oferecem apoio formal a cuidadores e suas famílias por meio de assistência domiciliar, centros-dia e hospitais para um período de curta permanência, bem como cuidadoras para revezamento nos cuidados com a casa e alimentação; podem ainda oferecer treinamento e apoio emocional como a organização de grupos de cuidadores. No Brasil é rara a oferta desses serviços formais com qualidade e quanto aos serviços dessa natureza, em geral gratuitos, não é garantida a sua qualidade. Os serviços públicos e privados são importantes para atender as demandas decorrentes das necessidades das pessoas idosas fragilizadas e dependentes, oferecendo suporte, orientação bem como alternativas de descanso e revezamentos para seus cuidadores (NERI; SOMMERHALDER, 2006).

Yuaso (2006) assinala a necessidade de pesquisas sobre os efeitos de diferentes programas direcionados aos cuidadores e a possibilidade dessas investigações contribuírem para melhorar as redes de apoio e de informação às famílias bem como contribuir na implementação de políticas que venham favorecer a saúde das pessoas idosas. Segundo Mafra (2011), é importante o cuidador receber cuidados especiais, levando em conta que cuidar de idoso dependente é uma tarefa desgastante e que poderá trazer o risco do cuidador se tornar posteriormente alguém que necessite também de cuidado: "No entanto, essas necessidades de saúde dos cuidadores, mesmo reconhecidas pelos programas de saúde do idoso, são frequentemente negligenciadas pelos serviços de saúde" (MAFRA, 2011, p. 8).

As desigualdades de gênero e a desigualdade das distribuições das tarefas condicionam a realidade do cuidado familiar. A quase totalidade do cuidado está em mãos de mulheres com menor nível educacional, sem emprego e condição social subalterna (KRMPOTIC; DE IESO, 2010). O cuidado familiar é atribuido às mulheres, seja o cuidado das crianças, de pessoas dependentes, de idosos ou de pessoas deficientes, pois a maternagem é naturalizada como capacidade feminina. A maternagem é a capacidade de cuidar, educar, como inerente à natureza feminina. É também uma construção sócio-histórica atrelada à moralidade que rege as ações dos indivíduos na sociedade (GUEDES; DAROS, 2009; FALEIROS, 2013). Quem geralmente assume essa responsabilidade são as filhas, esposas, noras, irmãs etc. A questão do cuidado, seja ele com doentes crônicos, deficientes ou idosos, tem sido geralmente responsabilidade da mulher (GUIMARÃES, 2008; CARDOSO; ROSALINI; PEREIRA, 2010).

\section{Dos direitos à Proteção Social da Pessoa Idosa}

Os direitos da pessoa idosa estão fundamentados na Constituição Federal (CF), que no seu artigo $1^{\circ}$ estabelece que o Brasil tenha como fundamento, entre outros, a cidadania e a dignidade da pessoa humana. Portanto esses fundamentos, além de assegurarem a todos os cidadãos os direitos constitucionais, oferecem respaldo à formulação dos direitos de proteção específicos direcionados às pessoas idosas (RIBEIRO, 2008). O artigo 203 da CF determina que o amparo ao idoso deve ser garantido pela família, pela sociedade e pelo Estado, devendo assegurar à pessoa idosa sua participação na comunidade, bem como defender sua dignidade, bem estar e o direito à vida. No $\S 1^{\circ}$ do referido artigo assinala-se que os programas de amparo aos idosos serão executados preferencialmente em seus lares; conforme o $\$ 2^{\circ}$, aos maiores de sessenta e cinco anos é garantida a gratuidade dos transportes coletivos urbanos. Outros artigos da CF trazem direitos de proteção a todos os cidadãos que também abarcam o grupo das pessoas idosas (BRASIL, 1988).

Destacam-se, dentre as leis de proteção à pessoa idosa, a Política Nacional do Idoso (PNI), no entanto, o Estatuto do Idoso (Lei n. 10.741, de 1..$^{\circ}$ de outubro de 2003) é a Lei máxima no tocante à proteção da população idosa. O modelo de proteção social definido pela CF de 1988 é constituído pela assistência social, a saúde e a previdência social como integrantes do sistema brasileiro de seguridade social. A proteção social ofertada pela política de assistência social tem a família como eixo estratégico para as ações sociais aos seus membros e é elemento principal de proteção (GOMES, 2009). Há que se considerar que,

Na discussão dos cuidados familiares tem-se um embate, por um lado as reformulações geradas a partir da crise do modelo de bem-estar social, dentro de um enfoque pluralista, sustenta o cuidado como resultado de um mix de opções entre o mercado, o Estado, a família e a comunidade. Por sua vez, no âmbito dos programas familiares, as orientações se desenvolvem em torno de duas posições conflitantes: a que apoia o regime familista - no qual se sustenta que a responsabilidade principal do bem estar corresponde às famílias, às mulheres e às redes de parentesco - e que o desafio está em conciliar o plano laboral e familiar. E aqueles que sustentam um regime de desfamilirização, delegando às instituições públicas, ao terceiro setor e ao mercado de serviços o cuidado (KRMPOTIC; DE IESO, 2010, p. 98). 
Concordamos com Krmportic e De Ieso (2010) que a questão do cuidado em uma sociedade desigual é ampla, envolve os diversos sistemas: de saúde, de seguridade e de proteção social. A questão do cuidado familiar precisa ser avaliada, discutida e planejada como uma política pública (MIOTO, 2010), incluindo a perspectiva de gênero para a ampliação da autonomia das mulheres, para que o cuidado deixe de ser inerente e imposto à mulher (GUEDES; DAROS, 2009).

\section{Aspectos metodológicos}

A pesquisa, descritiva e qualitativa, aborda o núcleo central das representações sociais: "Para Abric, o conteúdo da representação social está organizado em um sistema central (estável, rígido, consensual) e em um sistema periférico (mutável, individualizado)" (SOUZA; MENEZES, 2009, p. 91). As representações sociais expressam o senso comum com o qual um grupo de pessoas elabora o significado de um determinado objeto compartilhado na interação cultural em que vivem no cotidiano (MOSCOVICI, 2009). A pesquisa foi submetida ao Conselho de Ética em Pesquisa CEP e aprovada pelo parecer $630.980(14 / 04 / 2014)$.

Quanto aos participantes da pesquisa, são aqueles vinculados à Pastoral da Saúde, na Região Administrativa do Recanto das Emas/DF, pois esta acompanha pessoas acometidas por algum tipo de doença que os torna dependentes de ajuda para realizar tarefas diárias bem como tarefas esporádicas. Dentre estas, vinte e nove (29) são pessoas idosas, que recebem cuidados dos seus familiares e destes, quinze (15) foram selecionados por conveniência para a pesquisa. A seleção dos cuidadores foi realizada mediante uma lista elaborada por um membro da Pastoral da Saúde, contendo nome, endereço e telefone das pessoas idosas e o nome do cuidador familiar do idoso. O critério de seleção considerou que o cuidador poderia ter laços de parentesco ou não com idoso, desde que realizasse o cuidado de forma voluntária (BORN, 2008).

O instrumento utilizado foi o de evocação, contendo dez questões, sendo cinco sobre o cuidador familiar, cinco sobre o cuidado e sete questões sobre o perfil dos cuidadores. Foi usada a técnica de associação livre de palavras (TALP) para as expressões: cuidador familiar de idoso, e cuidado. Para a coleta de dados foi realizado o contato telefônico e agendamento das entrevistas. Após a leitura do Termo de Consentimento Livre e Esclarecido, conforme Resolução do Conselho Nacional de Saúde CNS 466/2012, anuência e assinatura pelo participante, o preenchimento do instrumento foi realizado pelo mesmo ou pela pesquisadora quando verificada dificuldade de leitura.

Para a análise dos dados, usou-se o software Evoc-2003. Após primeiro processamento no Evoc, foi realizada a leitura preliminar das respostas para verificar a possibilidade de agrupamento de palavras com significado sinônimo ou estreitamente relacionadas. Foi analisada a estrutura básica da representação social por parte dos cuidadores (facilidades, a visão do que é ser cuidador familiar de pessoa idosa). Dessas imagens, surgiram o núcleo central e a periferia da representação social. Para a interpretação foi considerada como guia a ilustração de Abric (2003), que apresenta peso diferente para cada quadrante na tabela de evocações.

\section{Tabela 1: Evocações hierarquizadas}

\begin{tabular}{llll}
\hline \multirow{2}{*}{ Frequência } & Forte & Zona do núcleo central & 1. ${ }^{\text {a }}$ periferia \\
& Fraca & 1. ${ }^{\text {a }}$ periferia & 2 . $^{\text {periferia }}$ \\
\hline & Primeiros colocados & Últimos colocados \\
\hline
\end{tabular}

Fonte: Elaboração própria. Montada a partir de Abric (2003).

Também foi utilizada a análise de conteúdo temática categorial para duas questões abertas com maior diversidade semântica e textual, como forma de corroboração da análise da Representação Social via Evoc. $\mathrm{Na}$ análise de conteúdo realizou-se a leitura flutuante, seguida do ordenamento de frases por significado semelhante, a ausência, presença, recorrência, e a inclusão dos temas nas categorias. Respeitou-se os critérios de exaustividade, representatividade, homogeneidade, pertinência, exclusividade e discussão entre co-pesquisadores (BARDIN, 2011). 


\section{Os resultados da pesquisa à luz da literatura}

O tempo médio de experiência como cuidador é superior a 10 anos, o que nos leva a cogitar que, por serem familiares muito próximos da pessoa idosa, já desempenhavam algumas tarefas relacionadas ao cuidado com o idoso no espaço domiciliar, mesmo antes da manifestação de doenças ou agravamento destas. Como as visitas foram realizadas no período da tarde, verificou-se que o período da manhã é intenso para os cuidadores nas AVD e AIVD (BORGES, 2011). É possível que os cuidadores familiares considerem os cuidados dedicados à pessoa idosa uma extensão das relações pessoais e familiares já estabelecidas antes da pessoa idosa adquirir dependência funcional (YUASO, 2006). O tempo diário dedicado aos cuidados com a pessoa idosa é de muitas horas, implicando em cansaço e exaustão e a possibilidade de desenvolver outras atividades fica comprometida, não havendo tempo para um respiro do próprio cuidador (MAZZA; LEFÉVRE, 2005; BORN, 2008; BORGES, 2011; MAFRA, 2011).

\section{Tabela 2: Perfil do cuidador familiar do idoso}

\begin{tabular}{|c|c|c|}
\hline Características & Masculino & Feminino \\
\hline Média de idade & $64 \operatorname{anos}(\mathrm{dp}=11)$ & 57 anos $(\mathrm{dp}=14)$ \\
\hline $\begin{array}{l}\text { Tempo médio de experiência } \\
\text { como cuidador(a) }\end{array}$ & $20 \operatorname{anos}(\mathrm{dp}=14,5)$ & $14 \operatorname{anos}(d p=11)$ \\
\hline Escolaridade & $\begin{array}{l}\text { Ensino fundamental incompleto } \\
\text { ( } 2 \text { pessoas) }\end{array}$ & $\begin{array}{l}\text { Ensino fundamental completo ( } 1 \text { pessoa) } \\
\text { Ensino fundamental incompleto ( } 10 \text { pessoas) } \\
\text { Ensino médio completo ( } 2 \text { pessoas) }\end{array}$ \\
\hline $\begin{array}{l}\text { Tempo diário na atividade de } \\
\text { cuidado }\end{array}$ & $24 \mathrm{~h}$ & $23 \mathrm{~h}$ \\
\hline Parentesco & Marido (2 pessoas) & $\begin{array}{l}\text { Filha ( } 7 \text { pessoas) } \\
\text { Esposa ( } 5 \text { pessoas }) \\
\text { Esposa do neto ( } 1 \text { pessoa) }\end{array}$ \\
\hline Outra atividade & Não (2 pessoas) & $\begin{array}{l}\text { Não ( } 10 \text { pess,oas) } \\
\text { Sim ( } 3 \text { pessoas) (copeira, costureira em casa, } \\
\text { vendedora autônoma) }\end{array}$ \\
\hline Estado civil & Casado (2 pessoas) & $\begin{array}{l}\text { Casada ( } 9 \text { pessoas }) \\
\text { Solteira ( } 4 \text { pessoas) }\end{array}$ \\
\hline Total de cuidadores(as) & 2 & 13 \\
\hline
\end{tabular}

Fonte: Elaboração própria(2014).

Nota: dp significa desvio padrão.

Em relação ao perfil dos cuidadores, a maioria (13) são mulheres, resultado semelhante ao de outros estudos (CARDOSO; ROSALINI; PEREIRA, 2010; FLORIANO et al., 2012), o que parece implicar a indissociabilidade da questão de gênero na função do cuidar que, ao longo da história até os dias atuais, tem sido delegada à mulher (FALEIROS, 2013). A média da idade das cuidadoras é de 57 anos $(\mathrm{dp}=14)$ havendo uma grande variação entre as idades. As mulheres, desde as mais jovens (filhas) às mais velhas (esposas), estão imbuídas da tarefa do cuidado. Observou-se também a existência de pessoas idosas de meia idade cuidando de pessoas idosas. Nesse cenário os cuidadores familiares idosos estão mais sujeitos aos impactos negativos do cuidado, uma vez que normalmente apresentam condições de vida semelhante ao idoso cuidado, além de também vivenciarem as mudanças relacionadas ao próprio envelhecimento. Cuidar de um idoso dependente pode suscitar nos cuidadores a preocupação com uma possível proximidade da própria dependência ou da sua finitude.

A baixa escolaridade e a não profissionalização entre os cuidadores pode indicar o adiamento de projetos pessoais em função do cuidado com a pessoa idosa (BORN, 2008). Questiona-se o quanto a qualidade da relação e do cuidado pode resistir diante dessa situação em longo prazo? 


\section{Núcleo Central e periferias da Representação Social}

Para determinar o núcleo central e o sistema periférico foram consideradas a frequência e a média ponderada da ocorrência dos termos produzidos. A frequência é o número de vezes que a palavra foi evocada e a média ponderada refere-se à ordem de evocação estabelecida pelos participantes no processo cognitivo de hierarquização. A frequência e a ordem média de evocação foram respectivamente 2 e 2,5. As palavras incluídas no primeiro quadrante foram as mais frequentes (Frequência 2) e as prioritariamente evocadas (Rang $<2,5$ ), por isso, provavelmente, são os elementos constituintes do núcleo central da representação social.

Conforme a Tabela 3, as palavras amor, carinho, paciência e saúde são as mais frequentes e prioritariamente evocadas - são o núcleo central -, constituindo com as demais palavras os elementos que dão significação à representação do cuidado na ótica dos cuidadores e, também, corrobora os sentimentos de afetividade apontados por Mafra (2011). O termo amor foi trazido à memória de dez participantes, sendo que para três foi prioritariamente evocado.

Os elementos periféricos encontram-se divididos nos outros três quadrantes. No segundo encontram-se os elementos: higiene e responsabilidade. Esses foram citados menos vezes, porém aparecem em primeiras posições. Nele reside a representação do que é ser cuidador, pois, como vem sendo discutidos (BORN, 2008; GOMES, 2009): o cuidador é aquele que se vê imbuído de cumprimentos de tarefas e do exercício da reponsabilidade, da reciprocidade, da obrigação moral para com o idoso. O que nos leva a referendar as palavras de Mioto (2010) a respeito da centralidade familiar na política de proteção social, pois o Estado deixa à família a tarefa e o custo de cuidar de um idoso com dependência funcional de saúde. Os participantes da pesquisa são os responsáveis pelo cuidado, apesar da baixa escolaridade e qualificação profissional bem como a sua sobrecarga de trabalho. O que parece atenuar um pouco a situação é o acompanhamento que recebem da Paróquia, pois eram cuidadores leigos que receberam algumas informações sobre o cuidado, mas que por ensaio e erro vão cuidando dos seus idosos, sem ter acesso ao mercado das empresas de atendimento domiciliar, sem seguro privado de saúde e sem suporte do Estado.

No terceiro quadrante estão os elementos zelo, atenção e dedicação, citados mais vezes, no entanto foram evocados em últimas posições. Portanto, essas palavras constituem-se na primeira periferia da representação social do cuidado e estão relacionados tanto as tarefas do cotidiano como a fatores afetivos do cuidado, pois para os participantes é necessário ter amor, carinho bem como "cuidar de tudo que a pessoa idosa precisa" (Participante 3). Esses elementos constituem demonstração de amor pela pessoa cuidada, uma vez que o amor, na concepção dos cuidadores, é algo primordial para assumir tarefas que demandam muito esforço físico e emocional como a de cuidar de um idoso com dependência funcional.

O cuidado com a saúde ( $2^{\circ}$ quadrante higiene, responsabilidade) envolve a administração de remédio, levar a consultas médicas assim como a preocupação com a higiene e alimentação, fazendo parte do cotidiano das mulheres cuidadoras, a maioria nesta pesquisa. É exigida disponibilidade e doação aos cuidadores e a paciência em compreender as atitudes dos idosos, ajudando-os a superarem momentos de crise ou de ansiedade. Esses sentimentos também se somam a outros: sofrimento e cansaço, pois a tarefa

Na maioria das vezes, quando tem uma pessoa idosa com dependência funcional, a família é obrigada a assumir a tarefa do cuidar, pois não dispõe de recursos financeiros para contratar o cuidador formal, bem como outros aparatos necessários ao cuidado da pessoa idosa. Geralmente quem assume esse papel na família é a mulher, pois, historicamente e pela lógica dos programas sociais de família, o cuidado é delegado à figura feminina. de cuidar é realizada por apenas uma pessoa.

Quanto à disponibilidade e doação, correspondem à segunda periferia de cuidador/cuidado, aparecendo em última posição e sendo menos citadas. Isto se ancora no simbolismo tradicional da dedicação, inclusive inculcado pela religião e a religiosidade. Em várias religiões, a dedicação ao próximo é dedicação a deus ou Deus, com renúncia pessoal, e significa abdicar ou adiar os próprios projetos pessoais (GUEDES; DAROS, 2009). Portanto se faz necessário a realização de estudos que deem visibilidade ao cuidador familiar como 
sujeito na prática de uma tarefa vinculada a um papel social, onde este não só atende as demandas subjetivas e imediatas da pessoa idosa como também traz soluções para um problema que é de toda a sociedade (YUASO, 2006; GUEDES; DAROS, 2009).

O ônus de cuidar é assumido como amor, que envolve carinho, paciência, zelo, dedicação e doação. Exige saúde de quem cuida, segunda dimensão do Núcleo Central, bem como higiene, responsabilidade, zelo e atenção a quem se cuida. Esse tripé do cuidado se articula nas evocações explicitadas: amor e dedicação, saúde de quem cuida e atenção a quem se cuida.

Tabela 3: Núcleo central e sistema periférico do cuidado e cuidador familiar do idoso

\begin{tabular}{|c|c|c|c|c|c|}
\hline \multicolumn{3}{|c|}{ Elementos centrais (cuidado) } & \multicolumn{3}{|c|}{ Elementos intermediários (cuidado) } \\
\hline Frequência e" 2 & 1 & Rang $<2,5$ & Frequência e" 2 & I & Rang $<2,5$ \\
\hline Amor & 10 & 2,200 & Zelo & 5 & 3,000 \\
\hline Saúde & 9 & 2,444 & Atenção & 3 & 3,000 \\
\hline Paciência & 5 & 2,400 & Dedicação & 3 & 3,333 \\
\hline Carinho & 4 & 1,500 & & & \\
\hline \multicolumn{3}{|c|}{ Elementos intermediários (cuidado/cuidador) } & \multicolumn{3}{|c|}{ Elementos periféricos (cuidador) } \\
\hline Higiene & 2 & 2,000 & Disponibilidade & 2 & 3,000 \\
\hline Responsabilidade & 2 & 1,000 & Doação & 2 & 4,000 \\
\hline
\end{tabular}

Fonte: Elaboração própria(2014).

A análise de conteúdo corroborou os resultados gerados pelo Evoc. A categoria cuidador familiar de idoso está relacionada à demonstração de dedicação, altruísmo e dar segurança. O cuidador familiar deixa a própria vida para viver a vida da pessoa idosa, ou seja, deixa de dar importância aos seus interesses pessoais, pois o tempo que dispõe é para realizar os cuidados com o sujeito idoso, sendo assim a sua vida circula em torno das necessidades da pessoa idosa (CARDOSO; ROSALINI; PEREIRA, 2010). A atenção implica oferecer segurança ao idoso, pois ser cuidador familiar na concepção dos participantes consiste em ter responsabilidade e desprendimento da própria vida em função de garantir a qualidade de vida da pessoa idosa cuidada. A representação de cuidador familiar vincula-se também ao imaginário do vocacional/obrigacional, representado como uma forma altruística de se dedicar ao idoso, doando-se, abdicando de outras aspirações para cumprir esse papel. É uma representação que encerra em si a contradição de um papel, que para a ação, o cuidado, tem a imagem do amor incondicional, mas por outro lado, para dar conta de todas as atividades necessárias para realizá-lo implica o sofrimento.

A categoria cuidado está associada a atividades cotidianas como o afeto, sofrimento e saúde. O sofrimento é compensado pelo sentimento de amor. Esses cuidadores estão sujeitos aos estressores de ordem emocional e social (FLORIANO et al., 2012). Em relação à fala de que "sem amor não dá para cuidar", presente nas expressões da maioria dos participantes, pode-se considerar que esteja associada à falta de amparo aos cuidadores, pois eles necessitam de suporte financeiro, psicossocial e de saúde (CARDOSO; ROSALINI; PEREIRA, 2010). O afeto implica, entre outros fatores, autocontrole emocional do cuidador familiar, objetivando não prejudicar a pessoa idosa, pois esta já se encontra em situação de fragilidade. $\mathrm{O}$ afeto consiste em sentir amor e carinho, gostar de cuidar e procurar atender todas as necessidades da pessoa idosa.

Os cuidadores precisam de suporte de uma política pública integrada de Assistência Social, Saúde e Previdência Social onde cada área possa atender respectivamente, as demandas de renda mínima, serviços domiciliares e de social. A profissão de cuidador vem sendo discutida no Congresso Nacional (BRASIL, 2012), mas ainda não foi aprovada. As cuidadoras são consideradas um valioso recurso tangível e intangível, e um meio para conciliar a esfera produtiva e reprodutiva, transformando uma necessidade típica do mundo privado em um problema público e objeto de políticas públicas (KRMPOTIC; DE IESO, 2010). 
Tabela 4: Análise de conteúdo e categorias

\begin{tabular}{|c|c|}
\hline Tema/frequência & Categoria cuidador familiar do idoso \\
\hline \multirow[t]{5}{*}{ Demonstrar dedicação (7) } & Ter muita paciência \\
\hline & Manter a calma quando ele fica nervoso \\
\hline & Não perder o equilíbrio \\
\hline & Ter força pessoal de si mesmo \\
\hline & Se entregar para a pessoa que cuidou de você anteriormente \\
\hline \multirow[t]{4}{*}{ Altruísmo (6) } & É deixar a minha vida para viver a do idoso \\
\hline & É doar-se pois exige tudo de mim \\
\hline & Dar atenção 24 horas e dedicar-se 24 horas \\
\hline & O tempo é só para ele \\
\hline \multirow[t]{4}{*}{ Dar segurança (3) } & Ter muita responsabilidade \\
\hline & Zelar e proteger \\
\hline & Ver sempre o que é melhor para ele \\
\hline & Categoria cuidado \\
\hline \multirow[t]{4}{*}{ Atividades quotidianas (9) } & Levar a missa \\
\hline & Acompanhar e não deixar só \\
\hline & Fazer companhia \\
\hline & Entreter e colocar para assistir TV, assistir junto \\
\hline \multirow[t]{6}{*}{ Afeto (6) } & Amar em primeiro lugar \\
\hline & Gostar de cuidar \\
\hline & Troca de cuidado e amor \\
\hline & Dar carinho e dividir alegrias, felicidade e tristezas \\
\hline & Dar tudo o que o idoso precisa \\
\hline & Demonstrar cuidado no dia a dia \\
\hline \multirow[t]{5}{*}{ Sofrimento (5) } & Esquecer a nossa própria vida para cuidar do idoso \\
\hline & É escravidão \\
\hline & Não posso sair, tenho que ficar em casa para cuida dele \\
\hline & É ser escrava por amor \\
\hline & Quando saio fico preocupada \\
\hline \multirow[t]{3}{*}{ Saúde (6) } & Ajudar no banho \\
\hline & Dar os remédios \\
\hline & Cuidar para não deixar cair \\
\hline
\end{tabular}

Fonte: Elaboração própria(2014).

\section{Considerações Finais}

Constatou-se que o convívio familiar impõe a um dos familiares a responsabilidade pelo cuidado, uma vez que a maioria dos cuidadores familiares assume essa tarefa por razões afetivas, culturais, de parentesco, entre outras. Na maioria das vezes, quando tem uma pessoa idosa com dependência funcional, a família é obrigada a assumir a tarefa do cuidar, pois não dispõe de recursos financeiros para contratar o cuidador formal, bem como outros aparatos necessários ao cuidado da pessoa idosa. Geralmente quem assume esse papel na família é a mulher, pois, historicamente e pela lógica dos programas sociais de família, o cuidado é delegado à figura feminina. O Estado, por sua vez, não estabelece e executa políticas de suporte familiar, assegurando precariamente a atenção à saúde no SUS e uma remuneração previdenciária desigualmente distribuída. Para atender as necessidades reais das famílias, a organização familiar é ampliada, por exemplo, incorporando um amigo, outro parente ou um membro da família mais diretamente ligado a pessoa idosa para assumir esse papel. Acredita-se que muitas vezes esse rearranjo familiar não é pensado, é imposto por problemas econômicos ou é emergente, pois cuida quem possui amor, tempo e disponibilidade para fazê-lo.

Os cuidadores familiares cuidam com amor dos idosos, uma vez que esse elemento foi prioritariamente evocado. Na análise de conteúdo das falas do cuidador familiar e do cuidado, esse sentimento é apresentado como motivador para a realização dos cuidados com a pessoa idosa. No entanto, é importante salientar que 
esses cuidadores precisam de atenção por parte do Estado e da sociedade, pois o contexto no qual estão inseridos constitui-se de um cenário complexo, uma vez que não há diretriz em lei ou regulação na política nacional de proteção ao idoso que oriente a atividade do cuidador familiar de pessoas idosas, deixando esse sujeito sem suporte, sozinho e na maioria das vezes despreparado para realizar a tarefa de cuidador. Ainda que existam algumas iniciativas de ações sociais por parte de instituições públicas e privadas que, além de serem ações focalizadas, não são suficientes para atender as necessidades dos cuidadores familiares, a importância de realizar estudos que investiguem o perfil de cuidadores familiares e as implicações que norteiam a atividade realizada por esses sujeitos, se dá na medida em que podem possibilitar a criação de políticas públicas, as quais ofereçam uma rede de suporte e amparo a esses cuidadores, contribuindo para sua qualidade de vida.

\section{Referências}

ABRIC, J. C. A abordagem estrutural das representações sociais. In: MOREIRA, A. S.P.; OLIVEIRA, D. C. (Org.). Estudos interdisciplinares de representação social. Goiânia: AB, p. 27-38, 2003.

BARDIN, L. Análise de Conteúdo. São Paulo, 2011.

BORGES, M.. Cuidar de Idosos: família e profissão. Juiz de Fora, 2011. Disponível em: <http://www.cuidardeidosos.com.br/tag/ profissao/feed/>. Acesso em: 17 abr. 2015.

BORN, T. (Org.). Cuidar Melhor e Evitar a Violência: Manual do Cuidador da Pessoa Idosa. Brasília: Secretaria Especial dos Direitos Humanos Subsecretaria de Promoção e Defesa dos Direitos Humanos, 2008.

BRASIL. Constituição (1988). Constituição da República Federativa do Brasil. Brasília: Câmara dos Deputados, 2010.

. Ministério do Desenvolvimento Social e Combate à Fome. Estatuto do Idoso: uma conquista de todos os brasileiros. Brasília, 2010.

. Ministério do Desenvolvimento Social e Combate à Fome. Política Nacional de Assistência Social (PNAS). Brasília, 2004.

Senado Federal. Projeto de Lei n. 4702/2012. Dispõe sobre o exercício da profissão de cuidador de pessoa idosa e dá outras providências. Brasília: Senado Federal, 2012. Disponível em: <http://www.camara.gov.br/proposicoesWeb/ fichadetramitacao?idProposicao=559429>. Acesso em: 06 mai. 2015.

CAMARANO, A. A.; PASINATO, T. Introdução. In: CAMARANO, A. A. (Org.). Os novos idosos brasileiros: muito além dos 60 ? Rio de Janeiro: IPEA, 2004.

CARDOSO, C. C. L.; ROSALINI, M. H. P.; PEREIRA, M. T. M. L. O Cuidar na Concepção dos Cuidadores: um estudo com familiares de doentes crônicos em duas unidades de saúde da família de São Carlos-SP. Serv. Soc. Rev., Londrina, v. 13, n. 1, p. 24-42, jul./dez. 2010. CATITA, P. A. L. As representações sociais dos enfermeiros do serviço de emergência face ao doente idoso. 2008. Dissertação (Mestrado em Comunicação em Saúde) - Universidade Aberta, Lisboa, 2008. Disponível em: <https: repositórioaberto.uab.pt/handle/ 10400.2/701>. Acesso em: 17 abr. 2015.

FALEIROS, V. P. Desafio de cuidar em Serviço Social: uma perspectiva crítica. Rev. Katálysis, v. 16, n. esp. p. 83-91, 2013. Disponível em: <http://dx.doi.org/10.1590/S1414-49802013000300006>. Acesso em: 17 abr. 2015.

. Envelhecimento no Brasil do Século XXI: transições e desafios. Argumentum, Vitória, v. 6, p. 6 - 21, 2014.

FERREIRA, A. R. S.; WONG, L. R. Cuidadores informais da população idosa com alguma limitação: estimativas indiretas: Brasil - 2000 a 2015. Ser Social, Brasília, p. 71-104, jan./jun. 2007.

FLORIANO, L. A. et al. Cuidado realizado pelo cuidador familiar ao idoso dependente, em domicílio, no contexto da estratégia de Saúde da Família. Texto contexto - enferm. v. 21, n. 3, p. 543-548, 2012. Disponível em: <http://dx.doi.org/10.1590/S0104-07072012000300008>. Acesso em: 17 abr. 2015.

GOMES, S. Políticas públicas de assistência social para idosos. In: SÃO PAULO. Secretaria Estadual de Assistência e Desenvolvimento Social do Estado. Políticas Públicas para a pessoa idosa: marcos legais e regulatórios. São Paulo: Fundação Padre Anchieta, p. 11-25, 2009. GUEDES, O. S.; DAROS, M. A. O cuidado como atribuição feminina: contribuições para um debate ético. Serv. Soc. Rev., Londrina, v. 12, n. 1, p. 122-134, jul./dez. 2009. Disponível em: 〈http://dx.doi.org/10.5433/1679-4842.2009v12n1p122〉. Acesso em: 17 abr. 2014. GUIMARÃES, R. Deficiência e cuidado: por quê abordar gênero nessa relação? Serviço Social, Brasília, v. 10, n. 22, p. 213-238, jan./ jun. 2008.

INSTITUTO BRASILEIRO DE GEOGRAFIA E ESTATÍSTICA. Pesquisa Nacional por Amostra de Domicílios (PNAD): síntese de indicadores 2009. Rio de Janeiro: IBGE, 2010.a.

. Síntese de indicadores sociais: uma análise das condições de vida da população brasileira. (Estudo e Pesquisas Informação Demográfica e Socioeconômica, n. 27). Rio de Janeiro: IBGE, 2010. b.

KRMPOTIC, C. S.; DE IESO, L. C. Los cuidados familiares: aspectos de la reproducción social a la luz de la desigualdad de género. Rev. Katálysis, v.13, n.1, p. 95-101, 2010. Disponível em: <http://dx.doi.org/10.1590/S1414-49802010000100011〉. Acesso em: 17 abr. 2015. MAFRA, S. C. T. A tarefa do cuidar e as expectativas sociais diante de um envelhecimento demográfico: a importância de ressignificar o papel da família. Rev. Bras. Geriatr. Geront. Rio de Janeiro, v. 14, n. 2, 2011. Disponível em: <http://revista.unati.uerj.br/scielo. php?script=sci_arttex\&pid=S1809-98232011000200015\&lng=pt $>$. Acesso em: 17 abr. 2015. 
MARQUES, M. J. F.; TEIXEIRA, H. J. C.; SOUZA, D. C. D. B. N. de. Cuidadoras informais de Portugal: vivências do cuidar de idosos. Trab. educ. saúde, Rio de Janeiro, v. 10, n. 1, p. 147-159, jun. 2012.

MAZZA, M. M. P. R.; LEFÉVRE, F. Cuidar em família: análise da representação social da relação do cuidador familiar com o idoso. Revista Brasileira de Crescimento e Desenvolvimento Humano, São Paulo, v. 15, n. 1, p. 1-10, abr. 2005.

MIOTO, R. C. Família; trabalho com família e Serviço Social. Serv. Soc. Rev., Londrina, v. 12, n. 2, p. 163-176, jan./jun. 2010. Disponível em: <http://dx.doi.org/10.5433/1679-4842.2010v12n2p163>. Acesso em: 17 abr. 2015.

MOSCOVICI, S. Representações sociais: investigações em psicologia social. Petrópolis: Vozes, 2009.

NERI, A. L.; SOMMERHALDER, C. As várias fases do cuidado e do bem-estar do cuidador. In: NERI, A. L. (Org.). Cuidar de idosos no contexto da família: questões psicológicas e sociais. São Paulo: Alínea, p. 9-58, 2006.

RIBEIRO, P. R. O. Os direitos da pessoa idosa na legislação. In: BORN, T. Cuidar melhor e evitar a violência: manual do cuidador de pessoa idosa. Brasília: Secretária Especial dos Direitos Humanos Subsecretaria Promoção e Defesa dos Direitos Humanos, p. 25-29, 2008. SÃO JOSÉ, J. Entre a gratificação e a opressão: os significados das trajetórias de cuidar de um familiar idoso. Sociologia - Revista da Faculdade de Letras da Universidade do Porto, n. temático - Envelhecimento demográfico, p. 123-150, 2012.

SOUZA, A. S.; MENEZES, M. R. Estrutura da representação social do cuidador familiar com idosos hipertensos. Rev.Bras. Geriatr. Gerontol., v. 12, n. 1, p. 87-102, 2009.

YUASO, D. R. Cuidar de cuidadores: resultados de um programa de treinamento realizado em domicílio. In: NERI, A. L. (Org.). Cuidar de idosos no contexto da família: questões psicológicas e sociais. São Paulo: Alínea, p. 165-199, 2006.

\section{Helga Cristina Hedler}

helgachedler@gmail.com

Doutora em Psicologia Social, do Trabalho e das Organizações pela Universidade Católica de Brasília (UCB) Professora no Curso de Serviço Social e no Mestrado em Gestão do Conhecimento e Tecnologia da Informação da Universidade Católica de Brasília (UCB)

\section{Vicente de Paula Faleiros}

vicentefaleiros@terra.com.br

Doutor pela Université de Montreal

Professor na Graduação e na Pós-graduação em Psicologia da Universidade Católica de Brasília (UCB)

\section{Marlene de Jesus Silva Santos}

marlenedjss@yahoo.com.br

Mestre em Política Social pela Universidade de Brasília (UNB)

Pesquisadora na área do trabalho com ênfase para o processo de desmonte administrativo do Estado e implicações para a política pública

\section{Maria Aparecida de Araújo Almeida}

mariacida2202@hotmail.com

Graduada em Serviço Social pela Universidade Católica de Brasília (UCB)

\section{UCB}

QS 07, Lote 01, EPCT, s/n

Âguas Claras - Distrito Federal - Brasil

CEP: 71966-700 